BSP retention at 25 min was $20 \%$ (normal $15 \%$ ) and $13 \%$ at $45 \mathrm{~min}$ (normal $<5 \%$ ). Her appetite returned with a $7 \mathrm{~kg}$ gain in weight. Her abdomen remained distended and her liver easily palpable.

Ten months after the initial presentation she was clinically unchanged and still taking occasional analgesics. Her haemoglobin was $12 \mathrm{~g} / 100 \mathrm{ml}$, alkaline phosphatase 9 King-Armstrong $u$, negative occult bloods in normal coloured stools and normal serum biochemistry except for a slightly raised 5 nucleotidase at $15 \mathrm{mu} / \mathrm{ml}$ (normal 4-11). Repeat BSP retention at $25 \mathrm{~min}$ was $45 \%$ and at $45 \mathrm{~min}$ was $40 \%$. Repeat liver scan showed no change in the size of liver but a more extensive patchy impairment of colloid uptake. Laparoscopy showed the right lobe of the liver to be completely encased in fat whilst the left appeared normal. Liver biopsy was unchanged.

\section{Comment}

We calculate that she took a total of $28 \mathrm{~kg}$ of Vick vapour rub over 2 years. Vick vapour rub contains menthol $2.82 \%$; camphor $5 \cdot 25 \%$; ol. terebinth $4.77 \%$; ol. eucalyp. $1.35 \%$; ol. myrist. $0.48 \%$; thymol $0.1 \%$; ol. cedri $0.45 \%$.
The aetiology of the iron deficiency anaemia is attributed to the chronic ingestion of Vick vapour rub because she did not respond to simple iron supplementation until the consumption of the offending substance was stopped. The mechanism is uncertain but the vapour rub may have caused gastric mucosal irritation with persistent occult blood loss or it may have interfered with the absorption of dietary iron. It is also possible that the transport to, and utilization of iron by the bone marrow could have been disturbed, as judged by the presence of toxic granulation of neutrophils. This may indicate that whatever vapour rub was absorbed may have affected granulopoiesis as well as erythropoiesis.

We believe her liver impairment to be due to the direct toxic effects of the absorbable constituents of Vick vapour rub. On biopsy, however, the liver showed only mild structural abnormalities compared with the disordered liver scan and liver function tests.

She states that she has not taken any Vick vapour rub for 1 year but we will follow her progress with interest. In particular we will continue to monitor her liver function which has not yet recovered.

\title{
An unusual self-inflicted injury of the breast
}

\author{
D. SAMPSON \\ Ch.M., F.R.C.S. \\ Department of Surgery, University of Cambridge
}

\begin{abstract}
Summary
A self-inflicted injury of the breast can present difficult diagnostic problems as is illustrated by the case report. A young woman had excoriated her left nipple causing profuse haemorrhage. Following excision of the nipple and a breast biopsy, the patient presented 1 month later with an abscess caused by the introduction of stones and gravel into the biopsy wound.
\end{abstract}

\section{Case report}

The 26-year-old unmarried woman first presented to the Surgical Clinic at Addenbrooke's Hospital with a 6-month history of massive bleeding from the left nipple. She had previously been seen at another East Anglian Hospital, where a diagnosis of dermatitis artefacta was suspected. Biopsy of the nipple there had shown changes of chronic inflammation.
Her relevant past history included a mild anxiety state at the age of 18 and an abortion at the age of 24. Following the abortion, a left breast abscess was treated with antibiotics.

On examination she looked extremely pale and was breathless on exertion. The left side of her brassiere was full of clotted blood. The right breast was normal, but on the left side the nipple was excoriated and was oozing bright blood from several areas. No discrete masses were palpable in either breast, but there was some thickening of the upper outer quadrant on the left side. Both axillae were clear. The patient was admitted to hospital, where the haemoglobin level was found to be $8.8 \mathrm{~g} / 100 \mathrm{ml}$ and an ESR was $62 \mathrm{~mm} / \mathrm{hr}$. Mammography was not carried out as the breast was too tender. She was observed on the ward and the bleeding continued. 
She was transfused $4 u$ of whole blood. In view of the continued bleeding, the nipple was excised, and a biopsy of the indurated area of the breast was taken through a separate incision. The patient made satisfactory recovery and the nipple wound healed well. The bleeding stopped. The biopsy wound was slightly infected but healed by first intention. Histology of the nipple showed chronic inflammatory changes only, and these were felt to be consistent with repeated trauma. The breast biopsy showed a dense hyaline stroma containing compressed ducts and lobules. The changes were thought to be consistent with previous inflammation.

One month following discharge from hospital, the patient was re-admitted complaining of an acutely painful lump in the left breast, together with a profuse discharge from the previous biopsy wound. The wound of the nipple excision was well healed (Fig. 1). On examination, there was a lump approximately $5 \mathrm{~cm}$ in diameter in the position shown in Fig. 1. It was extremely tender, and a strange crepitus

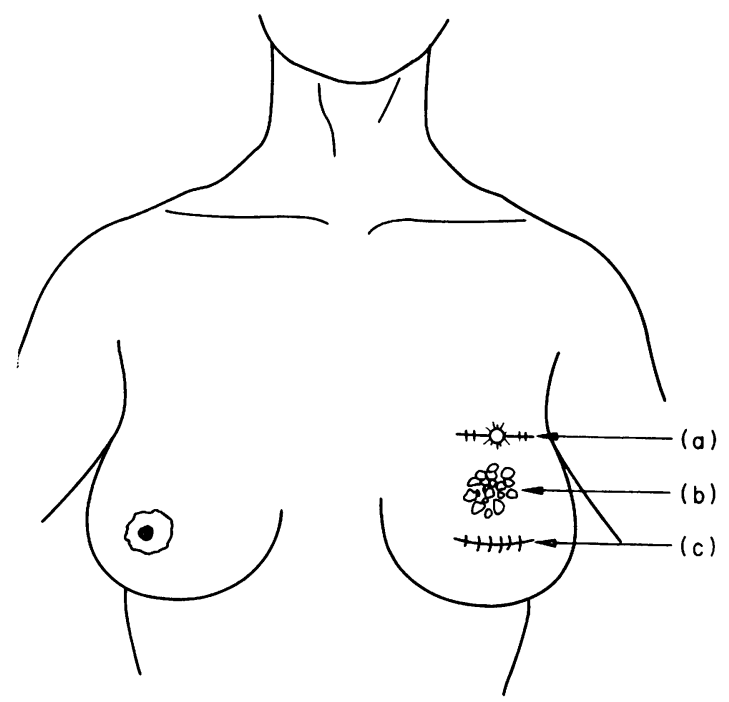

FIG. 1. Illustration of the physical findings on the patient's second admission to hospital. (a) Sinus in biopsy wound; (b) mass; (c) healed wound from nipple excision.

could be elicited. A small sinus was present in the upper wound through which yellow pus was discharging. The breast felt heavy. Her haemoglobin was $12.3 \mathrm{~g} / 100 \mathrm{ml}$ with an ESR of $69 \mathrm{~mm} / \mathrm{hr}$. A mammogram was carried out and this showed a densely calcified lesion in the upper half of the left breast (Fig. 2). Culture of the pus grew a heavy growth of Staphylococcus pyogenes and coliform organisms.

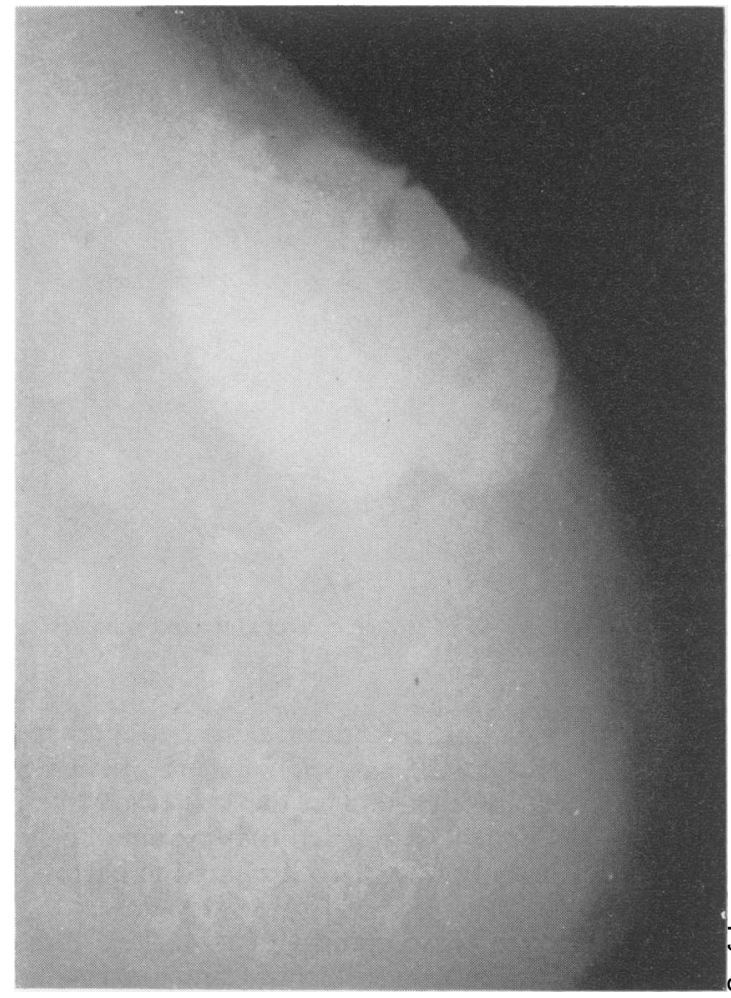

Fig. 2. Mammogram of the left breast showing a densely calcified multilocular lesion in the upper half.

It was decided that the mass should be removed and an incision was made directly over it. Approximately fifty stones mixed with sand and gravel were removed from an abscess cavity (Fig. 3). The walls of the cavity were curetted and a wide corrugated drain was inserted. The patient discharged herself against advice 2 days after the operation, with the drain still in place. She denied any interference with her breast, and did not know how the stones came to be there.

\section{Comment}

Spontaneous haemorrhage from the breast is a rare condition, and is almost always associated with the use of anticoagulant drugs (Mason, 1970; Tong, 1971). In this situation the haemorrhage occurs in the substance of the breast, and may be associated with massive gangrene. In the case described, anticoagulant drugs had not been taken and the massive haemorrhage occurred from the nipple, and no signs of gangrene were present. Similarly, an external blunt injury to the breast results in haemorrhage within the substance of the breast and even rupture of the breast tissue, but little in the way of external haemorrhage (Eastwood, 1972). 


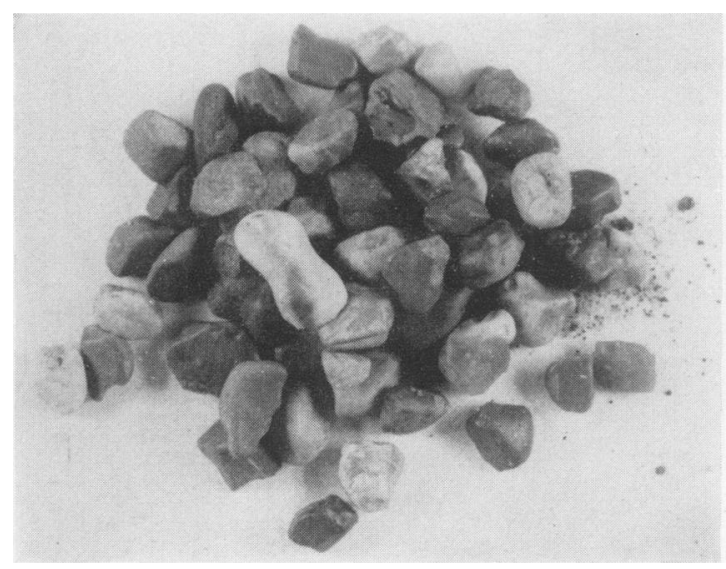

FIG. 3. Photograph of stones, gravel and sand removed from the left breast.

The absence of the features described perhaps should have led to the suspicion that the patient's injury was self-inflicted, but in the face of a strong denial by the patient, it was felt that excision of the nipple was the only way of controlling the haemorrhage.

The subsequent development of a calcified mass posed further diagnostic problems. Carcinoma of the breast is often seen as finely stippled calcification on mammography (Levitan, Witten and Harrison, 1964; Barker et al., 1969) and the massive opacities seen in our patient were clearly unlikely to represent malignant change. However, dense calcification can occur in fibro-adenomata, cystosarcoma phyllodes and in fat necrosis (Gershon-Cohen, 1970). Extensive calcification has also been described in chronic mastitis (France and O'Connell, 1970) and in retention cysts (Conway, 1936). It was not until the second exploratory operation that the true significance of the calcified lesion seen on mammography was realized, but even then the condition resembled a case reported as long ago as $\mathbf{1 7 7 9}$, in which stones were discharged through an opening in the breast of a woman who was said to have had a tumour for 30 years (Morgani, 1779).

The psychiatric aspects of the case presented are obscure since the patient would not allow a full evaluation, but it seems likely that the self-inflicted injury of the breast was a manifestation of guilt associated with her previous abortion (Silverman, 1970), or the expression of innate masochistic tendencies (Silverman, 1968).

\section{Acknowledgments}

I thank Mr W. G. Everett for permission to report on this case, and the Staff of the Medical Photography Department, Addenbrooke's Hospital, Cambridge, for the illustrations.

\section{References}

Barker, W.F., Sperling, L., Dowdy, A.H., Zeldis, L.J. \& LONGMIRE, W.P. (1969) Management of nonpalpable breast carcinoma discovered by mammography. Annals of Surgery, 170, 385.

Conway, J.H. (1936) Calcified breast tumors. American Journal of Surgery, 31, 72.

EASTWOOD, D.S. (1972) Subcutaneous rupture of the breast: a seat-belt injury. British Journal of Surgery, 59, 491.

France, C.J. \& O'ConNell, J.P. (1970) Osseous metaplasia in the human mammary gland. Archives of Surgery, 100 , 238.

Gershon-Cohen, J. (1970) Atlas of Mammography. SpringerVerlag: Berlin, Heidelberg, New York.

Levitan, L.H., WitTen, D.M. \& Harrison, E.G., JR (1964) Calcification in breast disease. Mammographic-pathologic correlation. American Journal of Roentgenology and Radium Therapy, 92, 29.

MASON, J.R. (1970) Haemorrhage-induced breast gangrene. British Journal of Surgery, 57, 700.

Morgani, G.B. (1779) De sedibus et causis morborum, 3, 42.

Silverman, S. (1968) Psychological Aspects of Physical Symptoms. Appleton-Century-Crofts: New York.

Silverman, S. (1970) Psychological Clues in Forecasting Physical Illness. Appleton-Century-Crofts: New York.

Tong, D. (1971) Haemorrhagic necrosis of the breast complicating anticoagulant therapy and mitral stenosis. British Journal of Surgery, 58, 624. 